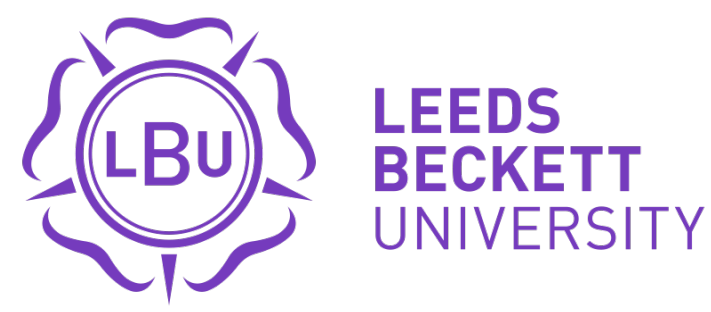

Citation:

Cardoso-Castro, PP and Sánchez-García, J and Soto-Pérez, M and Rodríguez-Magaña, A (2019) A Systems Science Approach to Inter-Organisational Complementarity in Tourism SMEs. Systemic Practice and Action Research. ISSN 1573-9295 DOI: https://doi.org/10.1007/s11213-019-09512-w

Link to Leeds Beckett Repository record:

https://eprints.leedsbeckett.ac.uk/id/eprint/6428/

Document Version:

Article (Accepted Version)

This is a post-peer-review, pre-copyedit version of an article published in Systemic Practice and Action Research. The final authenticated version is available online at: https://doi.org/10.1007/s11213019-09512-w

The aim of the Leeds Beckett Repository is to provide open access to our research, as required by funder policies and permitted by publishers and copyright law.

The Leeds Beckett repository holds a wide range of publications, each of which has been checked for copyright and the relevant embargo period has been applied by the Research Services team.

We operate on a standard take-down policy. If you are the author or publisher of an output and you would like it removed from the repository, please contact us and we will investigate on a case-by-case basis.

Each thesis in the repository has been cleared where necessary by the author for third party copyright. If you would like a thesis to be removed from the repository or believe there is an issue with copyright, please contact us on openaccess@leedsbeckett.ac.uk and we will investigate on a case-by-case basis. 


\title{
A systems science approach to inter-organisational complementarity in tourism SMEs
}

\author{
Jacqueline Y. Sánchez-García1, Juan E. Núñez-Ríos*2, Manuel Soto3, Pedro Pablo Cardoso-Castro4, \\ Alejandro Rodríguezs
}

1,2,3,5Universidad Panamericana. Escuela de Ciencias Económicas y Empresariales. Álvaro del Portillo 49, Zapopan, Jalisco, 45010, México.

4 School of Business and Law. Leeds Beckett University. Portland Crescent - The rose bowl, Leeds LS13HU, West Yorkshire, UK.

Corresponding author: jnunezr@up.edu.mx²

0000-0002-8328-62561, 0000-0002-3962-43342, 0000-0002-2298-20473, 0000-0002-5665-44714, 0000-0002-6311-77385

\begin{abstract}
This article proposes a model based on the integration of systemic mechanisms such as the soft systems methodology, partial least squares path modelling and the viable system model as an alternative for fostering complementarity (associativity) in Small and Medium Enterprises to improve responsiveness and adaptations in the tourism sector. The systemic method was adopted as a framework for the proposal. In this regard: 1 . The soft systems methodology was used to frame the problem and propose a construct for outlining a possible solution; the methodology included a questionnaire applied to 150 actors (including SME owners and managers and government officials). 2. Partial least squares path modelling was used to statistically validate the relationships in the construct. 3. Through the viable system model, the interactions between SMEs were reconsidered to recognise contextual impacts and foster complementarity. The goodness of fit of $70 \%$ obtained for the conceptual model suggests that complementarity, as an organisational form, is possible. The soft systems perspective is considered suitable because it deals with the complex nature of the problem (SME associativity). Although the results in this study apply to the Mexican context, we suggest that this potential limitation can be offset by the multi-methodological approach proposed here, allowing the model's application to all kinds of organisations. Hence, the observations in this paper are constrained to the organisational domain. This study may enable scholars and managers to improve communication channels as well as inter-organisational relationships, emphasising the increase in the responsiveness and adaptation capabilities to facilitate associativity between SMEs in the studied sector.
\end{abstract}

Keywords: Tourism, Viable System Model, Partial Least Squares Path Modelling, Systems Thinking, SMEs, Complementarity 


\section{Introduction}

In developing countries, small and medium-sized enterprises (SMEs) are components of the economy that require attention, as these companies represent more than $90 \%$ of the active units in such countries (OECD 2017). In the case of Mexico, intervention in these organisations is relevant because they contribute $70 \%$ of the gross domestic product (GDP) and provide 75\% of the regular jobs (INEGI 2017). Additionally, the tourism sector is a crucial activity for the Mexican economy, as it contributes to an estimated 35\% of GDP and generates approximately 4,060,700 direct jobs (CNET 2018). Tourism has also been proven to be an activity that promotes the relationships and associations among companies from different sectors and provides benefits to the localities that are involved in the services being offered (Nunez-Rios et al. 2019).

Derived from the existing literature, the ideas outlined in this work focus on SMEs in the tourism sector, which operate in a highly competitive and complex environment. These companies rely heavily on their organisational structure, collaborators and management mechanisms to be competitive. However, the discrepancy in the relationships between their operational, managerial and coordination components, as well as their lack of associativity with other SMEs, affects their ability to respond to the challenges and demands of customers and consequently affects their permanence in such a context.

Although SMEs are a primary and dynamic element of the tourism sector, they have structural problems and organisational asymmetries that affect their permanence, responsiveness and adaptation to the environment in which they operate. Some problems that these organisations face are the inconsistent management model that causes $70 \%$ of failures in the first two years (INEGI 2017); inefficient interactions between their operational, managerial and control units; low access to financial resources; a heterogeneous profile (CNET 2018); low capability to respond to tourist's requirements; a low sales percentage; and reduced investment in research and development (Maldonado-Guzmán et al. 2017). According to Sánchez-García et al. (2018) and Sánchez et al. (2017), these aspects constitute significant constraints that hinder the generation of inter-organisational relationships based on complementarity.

In accordance with Mwesiumo and Halpern (2016) and Recuero Virto et al. (2017), structures based on cooperation and complementarity are a type of linkage that generates adaptations, allowing companies turn a threat into an opportunity by seeking to unite the organisation's goals, initiatives and resources around common objectives to reduce costs, manage resources and be competitive in a global market. Nevertheless, the relationship between the adoption of best practices and organisational efficiency is unclear for tourism SMEs (Nikraftar and Hosseini 2016). Moreover, the lack of a clear understanding of this relationship presents the opportunity for SMEs to influence their capacity for collaboration and response to the environment from a systemic perspective (Armstrong 2019).

Based on the preceding discussion, this article suggests a conceptual model proposing interactions that are conducive to complementarity among SMEs in the tourism sector by integrating management and operations to respond to the environment. The conceptual model was built and validated with the participation of 150 actors, including managers and officials from government agencies. In this sense, the first objective was to apply the soft systems methodology (SSM) of Checkland (2001) to identify the components, structure the problem and propose a conceptual model to serve as a starting point for the process of change. The second objective was to estimate the validity of the relationships proposed in the construct, and to do so, partial least squares path modelling (PLS-PM) was used. The third objective was to enrich the conceptual model using the viable system model (VSM) of Beer (1985) to provide practical characteristics to the proposal and guide the analysis of the data.

\section{Literature review}

Empirical works using PLS-PM to address SMEs' inter-organisational relationships are usually centred in areas such as symmetry in business relationships (Gallarza et al. 2013), inter-organisational conflicts from the value chain perspective (Mwesiumo and Halpern 2016), business opportunities for SMEs (Nikraftar and Hosseini 2016), detecting the benefits of profit-centred growth (Presenza and Cipollina 2010), sustainability as a competitive advantage (Recuero Virto et al. 2017) and analysing organisational capabilities to adapt to the environment (Tiedemann et al. 2009). 
Valaei et al. (2017) mention that a significant anomaly of tourism SMEs is their ambiguity and organisational inconsistency, which affect their learning capabilities and results. By using structural equation modelling, the authors prove that aspects such as an exploitative learning strategy, an explorative learning strategy and creativity can be part of a solution process that contributes to SMEs generating innovation processes that allow them to remain active in the market. In this regard, Aboelmaged (2018) assess sustainability in SMEs' manufacturing practices, highlighting the importance of examining the relationships and impacts between specific components such as the environment and organisational structures. The author's findings, which use the PLS-PM approach, seem to indicate that stakeholders are one component of the environment that generates the most significant impact since their actions constitute a significant constraint for both the management capabilities of SMEs and the commitment of employees.

Authors such as Ali et al. (2017) and Zhang and Cao (2018) consider both the management style implemented in SMEs and the development of adaptive capacities to be factors that stimulate innovation. Through their studies, these authors report that this capacity of innovation occurs in internal terms, that is, to incentivise the strengthening of the decision-making processes, succession plans and, with less incidence, the development of employees. Jardon and Susana Martos (2012) point out that due to their organisational characteristics and management capacities, SMEs should adopt inter-organisational or collective efforts to increase efficiency and remain profitable and grow in a highly standardised market with aggressive competition. In this regard, the findings expressed by the authors suggest that for this collectivity to be a reality, it is necessary that the management, coordination and performance mechanisms are in agreeance.

The proper configuration and relationship between these components allow SMEs in the services sector to increase the quality of their processes and retain customers (Fararah and Al-Swidi 2013). Based on this idea, $\mathrm{Wu}$ et al. (2014) emphasise that due to the turbulent context in which these companies operate, it becomes almost impossible for them to compete and remain in the market if they do not choose to work through supply chains or as clustered companies in a collaborative manner oriented towards specific objectives. The cited articles also highlight the idea that to form beneficial interrelationships, these alliances must be based on trust, commitment, reciprocity and power. Additionally, the reported results indicate that the relationships among these components are beneficial for organisations because they foster collaboration and the transfer of information.

Considering the studies of Cheng (2011) and Mancinelli and Mazzanti (2009), inter-organisational relationships are critical for reducing the dysfunctional relationships and conflicts that may arise in the negotiation processes that SMEs carry out. In this sense, it has been strongly recommended that SMEs strengthen or transition towards a structural modality that allows them to be open to connectivity with other organisations. Regarding this idea, F-Jardon and Pagani (2016) agree with the authors cited so far and indicate that SMEs must make substantial efforts to develop their intellectual capital. Additionally, by employing PLS$\mathrm{PM}$, these authors establish that factors such as the environment, the decision processes and the efficiency between the operational units positively affect the propensity for SMEs to generate clusters that strengthen the competitiveness of the previously mentioned companies (Moreno and Casillas 2008). Johnston et al. (2004) evaluate the relationship between the actors who buy a service and those who provide a service, thus relating the level of confidence of the suppliers to the factors or characteristics of the cooperative behaviour of both businesses and buyers, which indicates that the perception of this relationship increases the possibility of the operational success of the organisations. Based on this idea, contributions have been made that evaluate the effect of the uncertainty perceived by managers of service SMEs. In this sense, the evidence obtained indicates that the threats perceived in the environment strongly affect the decision-making processes of managers and their generation and implementation of courses of action (Kalkhouran et al. 2017; Lejpras 2019).

Based on the above, it is considered pertinent to refer to another of the elements that are estimated to be relevant when evaluating the suitability of inter-organisational relationships. In this regard, Valaei (2017) indicates that the organisational structure cannot be ignored because it is a factor that should be considered by those in charge of solving problems in SMEs.

From the literature review above, it is inferred that various contributions are focused on assessing the degree of influence between variables and verifying the statistical suitability of a construct to predict the ability of a set of organisations to engage in inter-organisational relationships. Focusing on assessing the incidence between the variables of a construct raises, first, a problem and, second, a question. Regarding the problem, although collaborative models are statistically validated, few recommendations have been observed for their practical 
implementation. While some contributions address the practical dimension, they usually propose deployment under the horizontal or vertical integration scheme, and although both forms of linkage aim to strengthen the participation of companies in the market, these modalities are based on functionalist or structuralist criteria that tend to omit the equilibrated relationship between operational units and their management and control mechanisms.

Based on the above, a question arises regarding what tools can be integrated to support the construction and validation of a model that addresses inter-organisational complementarity. In this sense, the current work adopts the systems thinking approach because it is a comprehensive perspective that considers the impacts of the environment as well as the interaction between the mentioned elements. Following Romero-García et al. (2019), this approach is useful for dealing with tourism sector problems, as it frames multiple interactions at different levels with a transdisciplinary and participatory perspective. Under this framework, and applying soft modelling, Sellitto et al. (2018) proposes a systemic structure to understand the complexity of relationships in a network composed of companies mainly in the technology sector in a coopetitive framework or strategy. In this regard, Serrano et al. (2018) applies and tests this systemic structure in the clothing sector, which has led, through scenario planning, to the improvement of critical processes such as strategic planning and positively impacted the adaptive system behaviour.

Another systemic tool is system dynamics (SD), which, according to Sedarati et al. (2019), provides a robust framework that allows the integration of qualitative and quantitative elements to understand the complex interactions in social phenomena such as tourism. Although SD has commonly been used as a method to analyse strategies' robustness or the interdependencies between actors, it is still necessary to apply this tool at different levels, such as organisational or inter-organisational levels. For example, with this tool, Torres et al. (2017) propose an interesting idea in which a protocol is configured to assist decision-makers in small organisations to visualise possible scenarios and evaluate the course of action of their strategies, generating successful interventions in the participating organisations. Additionally, Torres et al.'s work contributes to the comprehensive measurement and evaluation of the effectiveness of strategies as well as to identify factors to achieve them. Carlisle et al. (2016) adopt a holistic perspective and integrate SD to evaluate and analyse the strategic planning of tourist spaces, finding that, in addition to the factors of the environment, it is necessary to promote the integration of actors, formalise alliances without failing to consider investment incentives to improve the utilisation of spaces and the offer to visitors.

Considering the ideas developed to this point, this article is intended to integrate the soft systems methodology (SSM), partial least squares path modelling (PLS-PM) and the viable system model (VSM). The soft systems methodology has been applied in various sectors; there are also precedents for its implementation in issues in management, collaboration and integration difficulties between SMEs (Antunes et al., 2016; Aslani et al., 2012; Klein et al., 2003; Krishnan and Scullion, 2017; Novani et al., 2014; Nunez-Rios et al., 2019; Proches and Bodhanya, 2015; Sánchez-García et al., 2018; Sgourou et al., 2012; Wang et al., 2015). One of the benefits that these works report is that the SSM allows consideration of the worldview of those involved and outlines models that emerge from the practical experience, complementing them with other forms of thinking to strengthen the study and construct possible solutions.

Within the systems thinking framework, the VSM is considered a useful tool for designing resilient organisations capable of rapidly adapting to the environment (Cardoso Castro 2019); its use also suggests a reflection on the application of dominant tools in management. Narvarte Arregui and Careaga Díaz (2015), Kirikova et al. (2018), Adham et al. (2019) and Rezaee et al. (2019) present precedents for the implementation of the VSM to address problematic situations in SMEs such as diagnosis, the design of collaborative schemes and the identification of capabilities to generate cooperation. First, Vahidi and Aliahmadi (2019) recognise that exploiting the strengths of the VSM requires tools that enable robust modelling and analysis. Second, according to Vahidi et al. (2019), only 2\% of VSM applications are oriented towards the resolution of problems in SMEs. In this regard, Schwaninger (2018) documents and strongly suggests the use of the VSM to analyse, integrate and coordinate organisational structures. 
To integrate the tools mentioned above, it is proposed that the SSM be used as a framework, since its flexibility allows one to address unstructured problems in which plurality and complexity are inherent. The SSM is grouped into two large blocks: block 1 (the real world) includes stages 1, 2, 5, 6 and 7. Block 2 (systems thinking) is composed of stages 3 and 4 (Checkland 2001). In this article, the development of the SSM will be as follows: Stages 1 and 2. Problem situation (unstructured and expressed): to identify components of the organisation and environment, which have a direct and medium relation with the problem and interact to affect the inter-organisational scheme. Stage 3. Root definition of relevant systems: using the CATWOE mnemonic (Customers, Actors, Transformation, Weltanschauung, Owner, Environment) to identify the elements required to shape the relevant systems or variables that will integrate the conceptual model as a basis for a possible solution. Stage 4. Conceptual model of the relevant systems: with the participation of the actors, a construct is proposed to establish the " must be/ideal" of the system to achieve its purpose and tackle the problem situation. Stage 5. Comparison between 4 and 2: the objective is to assess the pertinence of what has been formulated from the systems thinking for possible implementation in the real world. There are four ways of comparison: (a) general discussion; (b) question definition; (c) (historical) reconstruction; and (d) model overlay, with the last being selected because it allows the integration of quantitative tools. Thus, to comply with the objective in this stage, PLS-PM is used. Stage 6. Desired and feasible changes: those involved express the ideal state or improvements to the perceived problem (changes must be shared); it should be added that according to RamírezGutiérrez (2019) integrating and employing the VSM into the SSM framework is feasible to propose and express logic changes and restate relationships between organisations.

\section{Research methodology}

When systemic thinking applies to situations in which the intervention of the social component is high, it seeks to generate approaches that consider the worldview of those involved to propose processes of change, without circumventing the relationship with the context (Armstrong 2019). In this study, the systemic method was used and is considered suitable because its action field generates a bridge between methodological and practical aspects by, for example, outlining conceptual models to implement them in practice (Moore et al. 2017; Hanafizadeh et al. 2018). Additionally, the systemic method is sufficiently flexible for modelling soft systems or unstructured problematic situations in which "the what and how" are not so easy to recognise; therefore, this approach demands a pluralistic perspective or a mixed-method approach to be able to attend to different layers in a problem situation. From this perspective, the soft systems methodology (SSM) was used as a governing methodology for structuring the components of the problem (Shahabi et al. 2019). The SSM is flexible and allows for other methodological tools to be integrated to strengthen the study. Thus, PLS-PM and the VSM were used: the first tool was used to statistically validate the construct, and the second was used to move towards practice. It is considered appropriate to clarify that the construct mentioned was developed using the first two stages of the SSM. In this regard, the participants answered questions about the perceived problem situation, and their responses were used to formulate a conceptual model that was tested by the participants in several iterations until a consensual model was developed (Sánchez-García et al. 2018). Based on this, the SSM was applied as shown in Figure 1: 


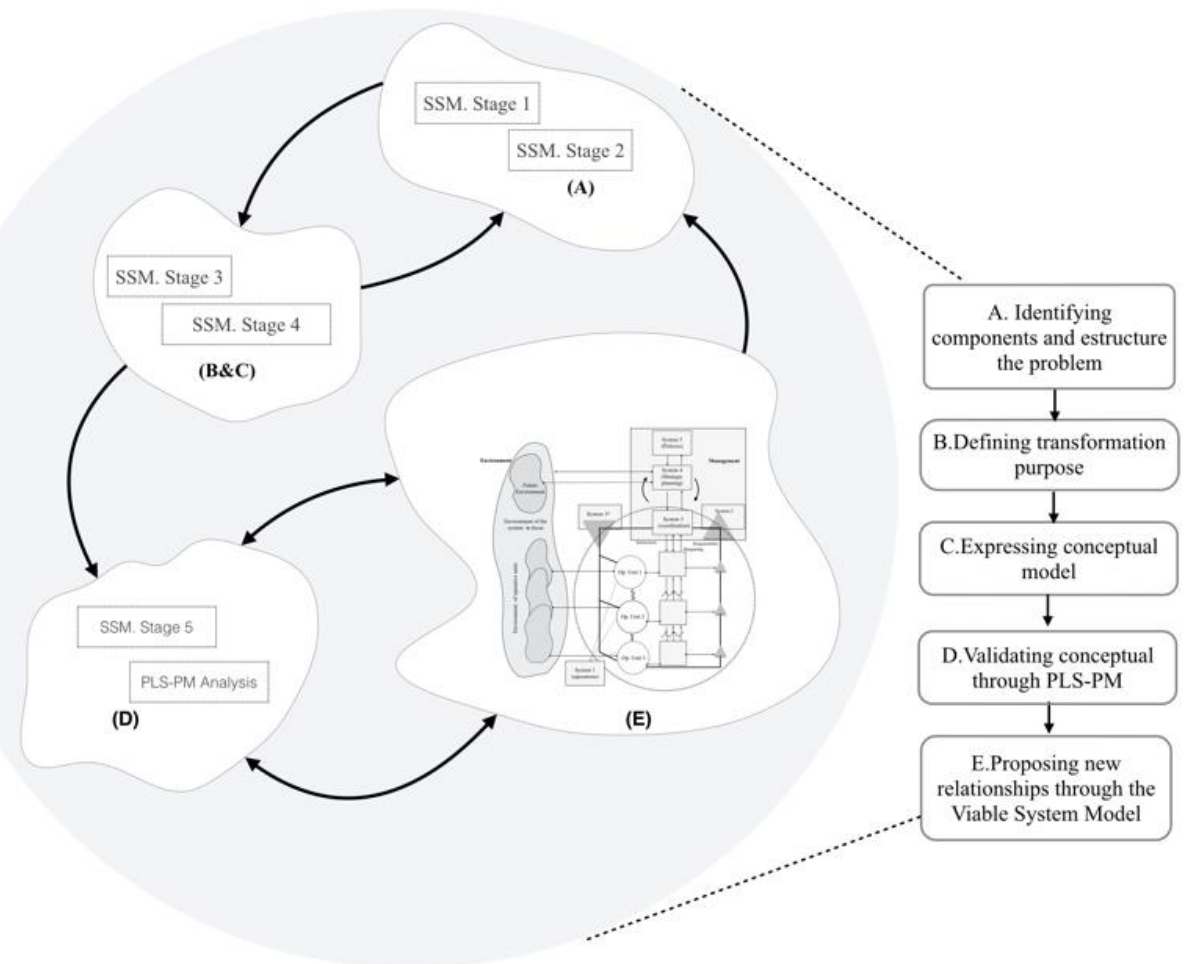

Figure 1. Methodology deployment

Source: Self-elaboration based on Checkland (2001)

\subsection{Information collection}

The items integrated the applied questionnaire 4 (commitment), 5 (communication, task communication, and performance communication), 6 (conflict regulation), 7 (co-ordination), 9 (effectiveness) and 10 (environment) from the Handbook of Organization Measurement (Price 1997). Table 1 shows the components of the instrument, which, in turn, consider the aspects described in the deployment of the SSM (next section). The variables considered by the questionnaire are Environment (ENV), Management (Mng), Operations (Ops), Organisational linkage (Olnk) and Complementarity (Cmp), which are based on the functions of the VSM (Beer 1985) and on the contributions of Mendola and Volo (2017) and Sarstedt et al. (2016). A 5-point Likert scale was used, with scores ranging from $1=$ disagree entirely to $5=$ completely agree; through this approach, the respondents assessed the relationships proposed in the conceptual model.

The sample size in this study was 150 participants, including managers and officials related to the regulation of the tourism sector based in Mexico. There is no rule of thumb regarding the minimum number of observations to conduct a study when using PLS-PM since how small or large the sample size should be depends on many factors. In this sense, the sample size in this study is justified by what is recommended by Sanchez (2013), who indicates that any analysis should include at least 100 observations. Additionally, Kline (2011) states that the sample size should include between 100 and 200 observations, and Kock (2018) stipulates that if the value of the path coefficient is unknown in advance, a reasonable minimum value for the sample size is 146 observations. It is necessary to mention that in this study, the sampling technique was used for convenience, and its application was $\mathrm{s}$ appropriate because, under a systems thinking framework, hypotheses were proposed to be tested at an early stage. This technique was also suitable due to the context specificity, the particularity of the situation under study and the access to information (Kerlinger 1986). 
Table 1 Variable and item descriptions

\begin{tabular}{|c|c|c|c|}
\hline Variable & Definition & Item & $I d$ \\
\hline \multirow{3}{*}{$\begin{array}{c}\text { Env } \\
\text { (Environment) }\end{array}$} & \multirow{3}{*}{$\begin{array}{l}\text { Elements from the context that affect business } \\
\text { operations or impact their response capabilities } \\
\text { (Gallarza et al., 2013) }\end{array}$} & $\begin{array}{l}\text { To achieve organisational goals, we } \\
\text { work cooperatively with other } \\
\text { organisations }\end{array}$ & Env1 \\
\hline & & $\begin{array}{l}\text { The organisation filters information } \\
\text { and focuses on what it does well }\end{array}$ & Env2 \\
\hline & & $\begin{array}{l}\text { Relationships with other } \\
\text { organisations are often marked with } \\
\text { conflicts }\end{array}$ & Env3 \\
\hline \multirow[b]{2}{*}{$\begin{array}{c}\text { Mng } \\
\text { (Management) }\end{array}$} & \multirow{2}{*}{$\begin{array}{l}\text { Activities or processes aimed at giving } \\
\text { congruence to the internal relationships of the } \\
\text { organisation to promote equilibrium before } \\
\text { changes in the environment (Kanwal et al., 2019; } \\
\text { Usakli and Kucukergin, 2018) }\end{array}$} & $\begin{array}{l}\text { The organisation owns and transmits } \\
\text { clear and precise objectives }\end{array}$ & Mng1 \\
\hline & & $\begin{array}{l}\text { Activities related to strategic } \\
\text { processes consider the organisation's } \\
\text { overall environment }\end{array}$ & Mng2 \\
\hline \multirow{2}{*}{$\begin{array}{c}\text { Ops } \\
\text { (Operations) }\end{array}$} & \multirow{2}{*}{$\begin{array}{l}\text { Basic operations of the organisation or courses of } \\
\text { action deployed to achieve general objectives } \\
\text { (Al-Dmour et al., 2016; Soltanizadeh et al., 2016) }\end{array}$} & $\begin{array}{l}\text { Each operative unit has clear } \\
\text { responsibilities to respond to a } \\
\text { specific function and environment }\end{array}$ & Ops1 \\
\hline & & $\begin{array}{l}\text { Operational units self-organise and } \\
\text { self-regulate because they are } \\
\text { provided with mechanisms for it }\end{array}$ & Ops2 \\
\hline \multirow{2}{*}{$\begin{array}{l}\text { Olnk } \\
\text { (Organisational } \\
\text { linkage) }\end{array}$} & \multirow{2}{*}{$\begin{array}{l}\text { Interdependencies between different organisations } \\
\text { that result in synergies or fruitful relationships for } \\
\text { the actors involved (Nikraftar and Hosseini, 2016) }\end{array}$} & $\begin{array}{l}\text { Internal and external communication } \\
\text { mechanisms are effective }\end{array}$ & Olnk1 \\
\hline & & $\begin{array}{l}\text { Coordination and feedback } \\
\text { mechanisms are effective }\end{array}$ & Olnk 2 \\
\hline \multirow{3}{*}{$\begin{array}{c}\text { Cmp } \\
\text { (Complementarity) }\end{array}$} & \multirow{3}{*}{$\begin{array}{l}\text { The ability of an organisation to take advantage of } \\
\text { its heterogeneous or distinctive capabilities to } \\
\text { collaborate with changes in the environment } \\
\text { (Usakli and Kucukergin, 2018) }\end{array}$} & $\begin{array}{l}\text { All organisational units are } \\
\text { interconnected and seek synergy }\end{array}$ & Cmp1 \\
\hline & & $\begin{array}{l}\text { The company identifies its } \\
\text { heterogeneous or distinctive } \\
\text { capabilities to enrich work with } \\
\text { other organisations }\end{array}$ & $\mathrm{CMp}_{2}$ \\
\hline & & $\begin{array}{l}\text { Diversity in knowledge fosters } \\
\text { cooperative work and equilibrium in } \\
\text { response to changes in the } \\
\text { environment }\end{array}$ & $\mathrm{Cmp}_{3}$ \\
\hline
\end{tabular}

Source: self-elaboration

According to Sanchez (2013), the data were processed using the following PLM-PM steps:

a. Translating the conceptual model into a structural model diagram.

b. Reviewing the unidimensionality of the latent variables in the measurement model through Cronbach's alpha coefficients and Dillon-Goldstein's rho, which must exceed 0.7. Complementarily, the first eigenvalue must exceed 1 , and the second must be less than 1 .

c. Ensuring that the factorial loading for each indicator is greater than 0.7 , as this indicator explains at least $50 \%$ of the variability of the latent variable.

d. Verifying by estimating the cross-loadings that there are no traitor indicators. That is, the higher factorial loading corresponds to the indicator to which it belongs.

e. Analysing the structural model, checking the determination coefficients $\mathrm{R}_{2}$ reporting the amount of variance in the dependent variables explained by their independent variables $\left(\mathrm{R}_{2}<0.2\right.$ low, $0.2<\mathrm{R}_{2}<$ 0.5 moderate, $\mathrm{R}_{2}>0.5$ high). Redundancy is also analysed because it indicates the independent variables' capability of predicting the dependent variables; that is, the higher the value is, the greater the capability is.

f. Running a bootstrapping analysis to validate meaningful relationships. This produces a confidence interval for each path coefficient related to the model. If this value is not 0 , it can be said that the hypothesis is significant with a $95 \%$ reliability.

g. Making calculations using the plspm package in R Studio. 


\section{SSM and PLS-PM results}

Given the above considerations, the application of the methodology is briefly described as follows:

Stages 1 and 2. Problem situation unstructured and expressed: According to the SSM, the components of the problem and the interactions between them are identified at this stage. It should be noted that for this, the dialogic process was used with the participants (Mulej et al. 2017); through the process, the participants named the elements that integrate the internal or immediately intermediate contexts and the environment in which the studied SMEs operate (Figure 2).

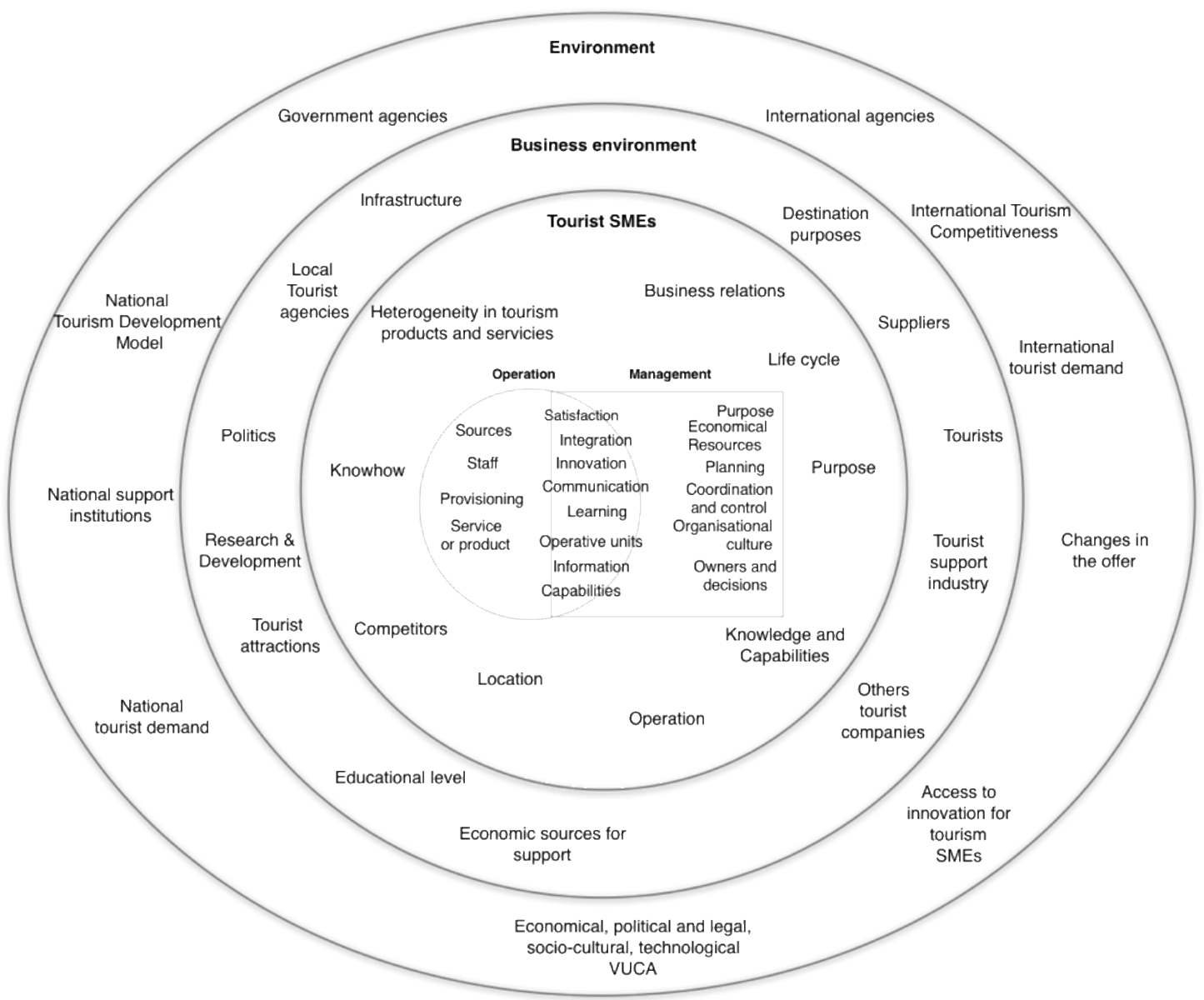

Figure 2. Elements of the problem situation

Source: self-elaboration based on Checkland (2001)

Based on stages 1 and 2, some conflicts identified at each level are described as follows:

- The first level (internal/organisational): SMEs lack a structure that allows for efficient interactions between management and operations. This affects the fulfilment of organisational objectives, knowledge management and the use of information to guide working groups towards efficiency.

- The second level (immediate context for SMEs): The organisational structure propitiates the duplicity of information and tasks (Núñez-Ríos et al. 2018). Additionally, companies do not have mechanisms that modulate relationships with other actors in their environment, such as customers, suppliers, other tourism SMEs, and government agencies.

- The third level (environment): Tourism SMEs do not have mechanisms to attenuate the changes caused by the relevant actors in the sector or obtain information from the environment to translate it into plans that contribute to the growth and beneficial interaction of the companies. 
Stages 3 and 4. Root definition of the relevant systems and conceptual model: In these phases, an alternative should be outlined to improve the problem situation. In this regard, the CATWOE mnemonic (Table 2) was used to include the essential and sufficient elements in the improvement process. In that sense, the improvement or transformation expressed was as follows: "A viable model that integrates tourism SMEs based on the coherent interaction of their operation units, management mechanisms and organisational linkage capabilities to propitiate adaptation and equilibrium to their current environment". Based on this definition, in the next stage, a conceptual model was generated to express how the variables could be related to promoting organisational complementarity and contribute to improving the responsiveness of the companies under study (Figure 3). At this stage, the conceptual model must integrate essential activities to support the transformation process (Table 3). In this regard, a construct was presented with possible relationships to strive for complementarity between the mentioned SMEs.

Table 2 CATWOE elements

\begin{tabular}{cl}
\hline $\begin{array}{c}\text { Client } \\
\text { Actor }\end{array}$ & Managers, other lodging SMEs, guests, inputs and services suppliers \\
Transformation & Coherent integration of operations, management, and control organisms allow for a useful relationship with \\
organisations and for improving their capabilities to adapt to the complex environment & The complexity increases with the number of interrelationships; therefore, it is necessary to make the inter- \\
Weltanschauung & organisational relationships more useful to support each organisation and to adapt to its environment \\
Owner & SME owners and managers \\
Cameras and support institutions, other tourism SMEs, tourism regulator organisations, providers of labour &
\end{tabular}

Source: based on Checkland (2001)

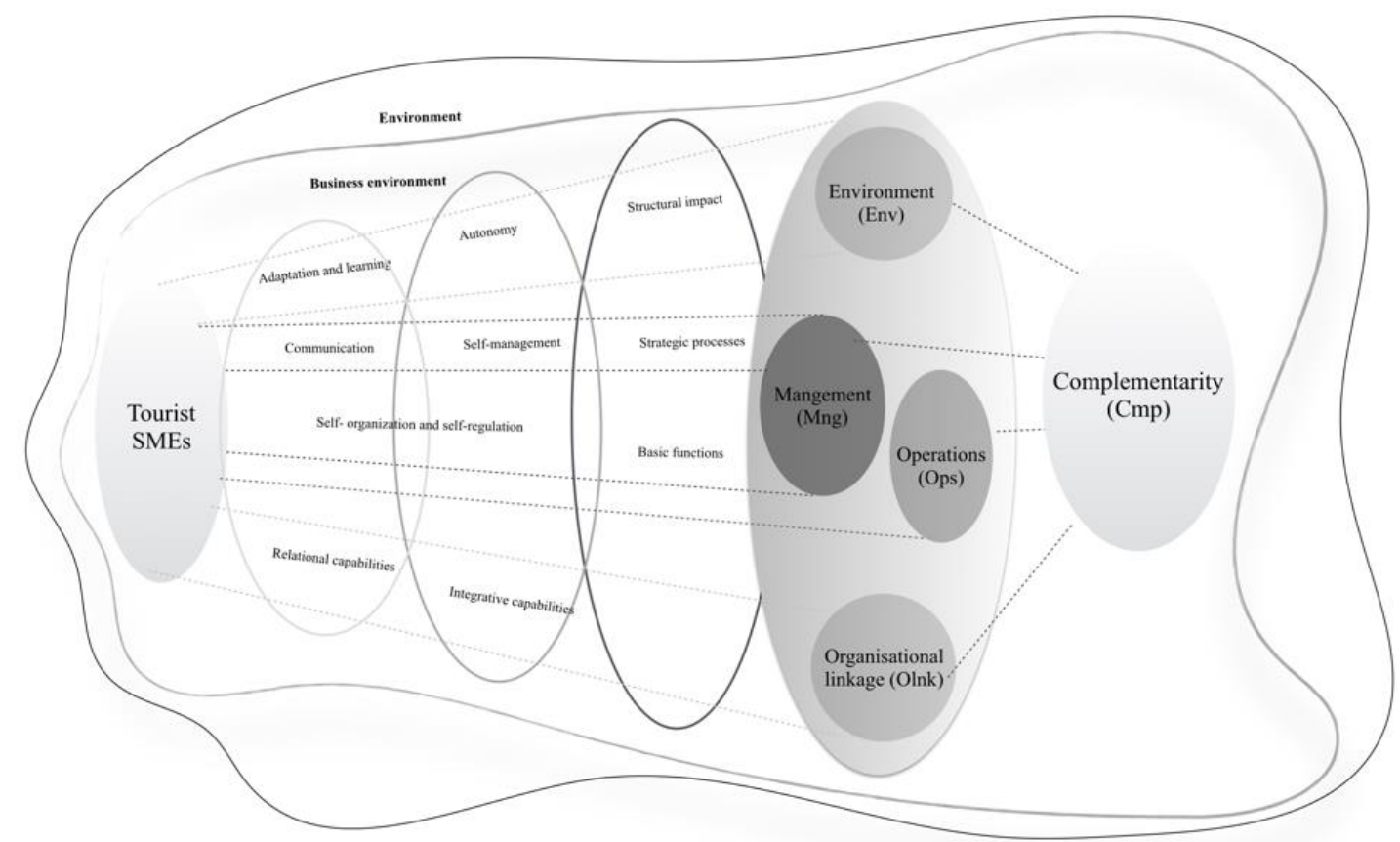

Figure 3 Conceptual model

Source: based on Stages 3 and 4 of the SMM (Checkland 2001)

From the SSM point of view, a hypothesis can be formulated precisely from the development of stages 3 and 4. In this regard, the following general hypothesis for this article was raised: the suggested relations between 
the variables considered in the conceptual model justify the construction of a VSM to foster inter-organisational complementarity among tourism SMEs.

Table 3 Variables and items for the conceptual model with corresponding mean $(\mu)$ and standard deviation $(\sigma)$ values

\begin{tabular}{|c|c|c|c|c|c|c|c|c|c|c|c|c|c|c|c|}
\hline Variable & $I d$ & $\mu$ & $\sigma$ & Env1 & Env2 & Env3 & Mng1 & Mng2 & Opsl & Ops2 & Olnk1 & $O \operatorname{lnk2}$ & Cmpl & Cmp2 & $\mathrm{Cmp3}$ \\
\hline \multirow{3}{*}{ Environment } & Env1 & 4.48 & 0.57 & 0.33 & 0.19 & 0.11 & 0.16 & 0.18 & 0.19 & 0.16 & 0.17 & 0.14 & 0.19 & 0.20 & 0.19 \\
\hline & Env2 & 4.48 & 0.57 & $0.56^{* *}$ & 0.33 & 0.10 & 0.11 & 0.16 & 0.19 & 0.13 & 0.14 & 0.14 & 0.18 & 0.16 & 0.18 \\
\hline & Env3 & 4.46 & 0.59 & $0.33 * *$ & $0.29 * *$ & 0.34 & 0.19 & 0.14 & 0.17 & 0.23 & 0.19 & 0.13 & 0.14 & 0.17 & 0.18 \\
\hline \multirow{2}{*}{ Management } & Mng $_{1}$ & 4.42 & 0.62 & $0.44 * *$ & $0.32 * *$ & $0.53 * *$ & 0.38 & 0.18 & 0.19 & 0.26 & 0.22 & 0.16 & 0.17 & 0.16 & 0.21 \\
\hline & $\mathrm{Mng}_{2}$ & 4.39 & 0.62 & $0.51^{* *}$ & $0.46^{* * *}$ & $0.39 * *$ & $0.46^{* *}$ & 0.38 & 0.22 & 0.19 & 0.19 & 0.15 & 0.20 & 0.18 & 0.24 \\
\hline \multirow{2}{*}{ Operations } & Ops1 & 4.47 & 0.56 & $0.57 * *$ & $0.59 * *$ & $0.51 * *$ & $0.55^{* *}$ & $0.63^{* *}$ & 0.31 & 0.21 & 0.21 & 0.19 & 0.21 & 0.19 & 0.25 \\
\hline & Ops2 & 4.52 & 0.53 & $0.53 * *$ & $0.42 * *$ & $0.72 * *$ & $0.78 * *$ & $0.58 * *$ & $0.69 * *$ & 0.28 & 0.24 & 0.16 & 0.18 & 0.17 & 0.22 \\
\hline \multirow{2}{*}{$\begin{array}{l}\text { Organization } \\
\text { al linkage }\end{array}$} & Olnk1 & 4.55 & 0.52 & $0.58 * *$ & $0.48 * *$ & $0.62 * *$ & $0.69 * *$ & $0.59 * *$ & $0.74 * *$ & $0.88^{* *}$ & 0.27 & 0.17 & 0.18 & 0.18 & 0.21 \\
\hline & Olnk2 & 4.52 & 0.55 & $0.44 * *$ & $0.43 * *$ & $0.41 * *$ & $0.48 * *$ & $0.45^{* *}$ & $0.62 * *$ & $0.54 * *$ & $0.61 * *$ & 0.30 & 0.19 & 0.18 & 0.19 \\
\hline \multirow{3}{*}{$\begin{array}{l}\text { Complement } \\
\text { arity }\end{array}$} & $\mathrm{Cmp}_{1}$ & 4.54 & 0.5 & $0.66^{* *}$ & $0.62 * *$ & $0.49 * *$ & $0.54 * *$ & $0.64 * *$ & $0.75 * *$ & $0.66^{* *}$ & $0.71^{* *}$ & $0.70 * *$ & 0.25 & 0.24 & 0.22 \\
\hline & $\mathrm{Cmp}_{2}$ & 4.51 & 0.52 & $0.66^{* *}$ & $0.52 * *$ & $0.55 * *$ & $0.49 * *$ & $0.56^{* *}$ & $0.67 * *$ & $0.62 * *$ & $0.66^{* *}$ & $0.63 * *$ & $0.91 * *$ & 0.27 & 0.21 \\
\hline & $\mathrm{Cmp}_{3}$ & 4.51 & 0.52 & $0.64 * *$ & $0.60^{* *}$ & $0.60 * *$ & $0.66 * *$ & $0.75 * *$ & $0.85 * *$ & $0.78 * *$ & $0.78 * *$ & $0.65^{* *}$ & $0.85^{* *}$ & $0.76^{* *}$ & 0.27 \\
\hline
\end{tabular}

Source: self-elaboration using the plspm package in Rstudio

Based on the general hypothesis expressed up to this point, the literature review and the contributions of Cheng (2011), Kalkhouran et al. (2017), Aboelmaged (2018) and Usakli and Kucukergin (2018), the working hypotheses that fit the conceptual model of this article are expressed as follows:

- $H_{1}$ : Environment components (Env) significantly affect the management (Mng) of the studied organisations. According to Cheng (2011), establishing the environment is critical for management.

- $H_{2}$ : Environment components (Env) affect and condition the formation of organisational relationships (Olnk). Regarding this, Gallarza et al. (2013) and Wu et al. (2014) agree on the relationship between these variables.

- $H_{3}$ : Management in the organisations (Mng) positively influences the response capability of operations (Ops), as affirmed by Fararah and Al-Swidi (2013) and Jardon and Susana Martos (2012), who emphasise that the type of management shapes the operational responses.

- H4: Management components (Mng) condition organisational linkage (Olnk). In this sense, Usakli and Kucukergin (2018) agree that some components can cause organisational linkage.

- $H_{5}$ : The integration in operation (Ops) fosters inter-organisational linkage (Olnk), which follows Zhang and Cao (2018), who suggest considering operations to generate conditions for interorganisational linkage.

- H6: Inter-organisational linkage (Olnk) propitiates complementarity (Cmp) between SMEs. Usakli and Kucukergin (2018) indicate that this is a path that needs to be explored.

\subsection{Conceptual model comparison using PLS-PM}

From the systems thinking and soft modelling perspective, PLS-PM is an appropriate tool for validating the proposed model, as it stimulates a synthesis process by translating theoretical concepts into blocks of measurable variables. PLS-PM helps address unstructured situations as one-dimensional problems and allows for the assessment of multiple relationships, offering conclusions from an integrative perspective (Nakamori 2003; Rousseau et al. 2018). In this article, PLS-PM was used to verify whether the relationships proposed in the conceptual model are coherent and fit the problematic situation under study using the significance index of the variables. Based on this approach, Table 4 indicates the values for the Cronbach's alpha and DillonGoldstein's rho of each latent variable, with Cronbach's alpha values above 0.70 in most cases. According to 
Esposito Vinzi et al. (2010) and Marcoulides et al. (2009), Dillon-Goldstein's rho is considered to be a better indicator for internal consistency, and in this study, all variables obtained rho values above 0.80 . These measurements are consistent with the results of the eigenvalues, as the first is above 1, and the second is below 1. These three statistical tests corroborate the unidimensionality of the items to measure the latent variable to which they correspond. Additionally, factor loadings above 0.70 were obtained for each indicator, confirming their reliability in measuring the latent variables (Table 6); following Sanchez (2013), when this value is above 0.70 , it ensures that the item explains at least $50 \%$ of the variability of the latent variable.

Table 4 Cronbach's alpha $(\alpha)$, DG rho $(\rho)$, and first and second eigenvalues to measure the internal consistency of each

\begin{tabular}{|c|c|c|c|c|}
\hline & $\alpha$ & $\rho$ & eig.1 & eig.2 \\
\hline Environment (Env) & 0.66 & 0.82 & 1.81 & 0.76 \\
\hline Mangement (Mng) & 0.63 & 0.84 & 1.46 & 0.54 \\
\hline Operations (Ops) & 0.82 & 0.92 & 1.69 & 0.31 \\
\hline Organisational linkage (Olnk) & 0.76 & 0.89 & 1.62 & 0.38 \\
\hline Complementarity (Cmp) & 0.94 & 0.96 & 2.69 & 0.24 \\
\hline
\end{tabular}

Source: self-elaboration using the plspm package in Rstudio

Concerning the reliability analysis of each item (Figure 4), the loadings for each indicator are shown with their respective block. These measurements report the composition, relative importance and behaviour of each item in each latent variable (Vihari et al. 2018).

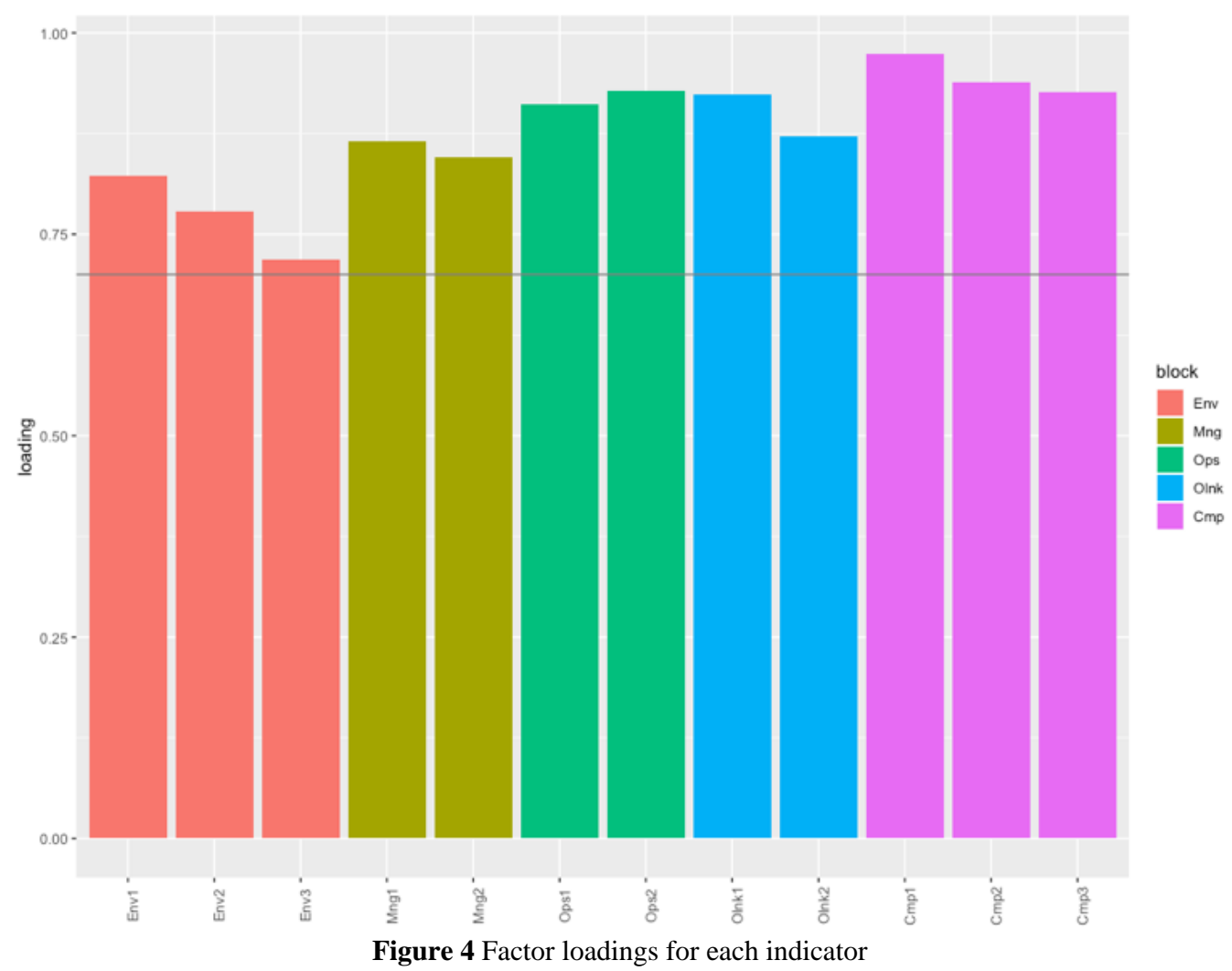

Source: self-elaboration using the plspm package in Rstudio 
Table 5 also indicates that there is discriminant validity for each of the items because the ranges of the factorial loadings do not overlap $[\lambda]$ with the cross-loading ranges $[C-\lambda]$. It is possible to confirm the absence of traitor indicators because the intervals of the factorial loads report higher values than the cross-loading intervals (Sanchez, 2013). This model fits validity requirements because each indicator reports a more significant factorial loading on its latent variable compared to the other variable (Latan 2018). According to Fornell and Larcker (1981), the discriminant validity between two latent variables can be tested if the shared variance $R_{2}$ is lower than the average variance extracted $\left(R_{2}<A V E\right)$ (Table 7). Therefore, Fornell and Larcker's test is fulfilled in the proposed model. Convergent validity is assumed if the range of the factorial loads $[\lambda]$ is narrow and the value of the lower loading for each latent variable is higher (Müller et al. 2018).

Table 5 Factor loadings $(\lambda)$ and cross-loadings $(\mathrm{C}-\lambda)$ for each indicator

\begin{tabular}{lcc}
\hline & {$[\lambda]$} & {$[C-\lambda]$} \\
\hline Env1 & 0.82 & $0.56-0.69$ \\
Env2 & 0.78 & $0.46-0-62$ \\
Env3 & 0.72 & $0.55-0.68$ \\
Mng1 & 0.87 & $0.57-0.73$ \\
Mng2 & 0.85 & $0.59-0.69$ \\
Ops1 & 0.91 & $0.69-0.81$ \\
Ops2 & 0.93 & $0.73-0.82$ \\
Olnk1 & 0.92 & $0.73-0.89$ \\
Olnk2 & 0.87 & $0.55-0.70$ \\
Cmp1 & 0.97 & $0.69-0.79$ \\
Cmp2 & 0.94 & $0.62-0.75$ \\
Cmp3 & 0.93 & $0.80-0.89$ \\
\hline
\end{tabular}

Source: self-elaboration using the plspm package in Rstudio

The quality of the model can be determined using the determination coefficients $\mathrm{R}_{2}$ that represent the level of variance of each dependent variable, which is explained by the independent variable. For the endogenous variable management, the $\mathrm{R}_{2}$ value is moderate, while for operations, organisational linkage and complementarity, the level is high, as shown in Table 6 . Additionally, Table 6 shows the results regarding redundancy for the variables, which, in all variables, is above 0 ; this guarantees the predictive relevance of the construct. Additionally, regarding the predictive quality of this model, it is possible to analyse the goodness-offit value; for this model, this value proved to be 0.7 , and values greater than or equal to 0.7 are considered acceptable.

Table 6 Type of variable, R2, redundancy and average variance extracted (AVE) values by latent variable

\begin{tabular}{lcccc}
\hline & Type & $R 2$ & Redundancy & AVE \\
\hline Environment (Env) & Exogenous & 0.00 & 0.00 & 0.60 \\
Management (Mng) & Endogenous & 0.46 & 0.34 & 0.73 \\
Operations (Ops) & Endogenous & 0.66 & 0.56 & 0.85 \\
Organisational linkage (Olnk) & Endogenous & 0.76 & 0.61 & 0.81 \\
Complementarity (Cmp) & Endogenous & 0.67 & 0.60 & 0.90 \\
\hline
\end{tabular}

Source: self-elaboration using the plspm package in Rstudio

Figure 5 shows the transition from the conceptual model that resulted from the SSM to a path model in terms of PLS-PM. The figure also indicates the path coefficients for the proposed relationships from the independent variables towards the dependent variables. The diagram allows for inferring that interorganisational relationships (Olnk) between the small and medium-sized tourism companies are possible, and this fosters a high probability of the complementarity condition ( $\mathrm{Cmp}$ ) between the studied organisations. It is stressed that the factors concerning the environment (Env) and the management components (Mng) do not, by themselves, constitute elements that significantly and directly have an influence in a framework that facilitates mutual relationships. However, it is relevant to mention that Env only has a significant impact on Cmp when the variables Mng, Ops and Olnk are integrated in this relationship. This integration suggests that the promotion 
of complementarity is necessary for management to generate the proper strategies and adaptations to deal with the changes caused by the environment and transmit clear instructions to the operating units, which is a condition that allows for relationships among SMEs. This concept is mentioned in consideration of the bootstrapping results of Table 7 .

Figure 5 Path coefficients for the proposed relationships in the model

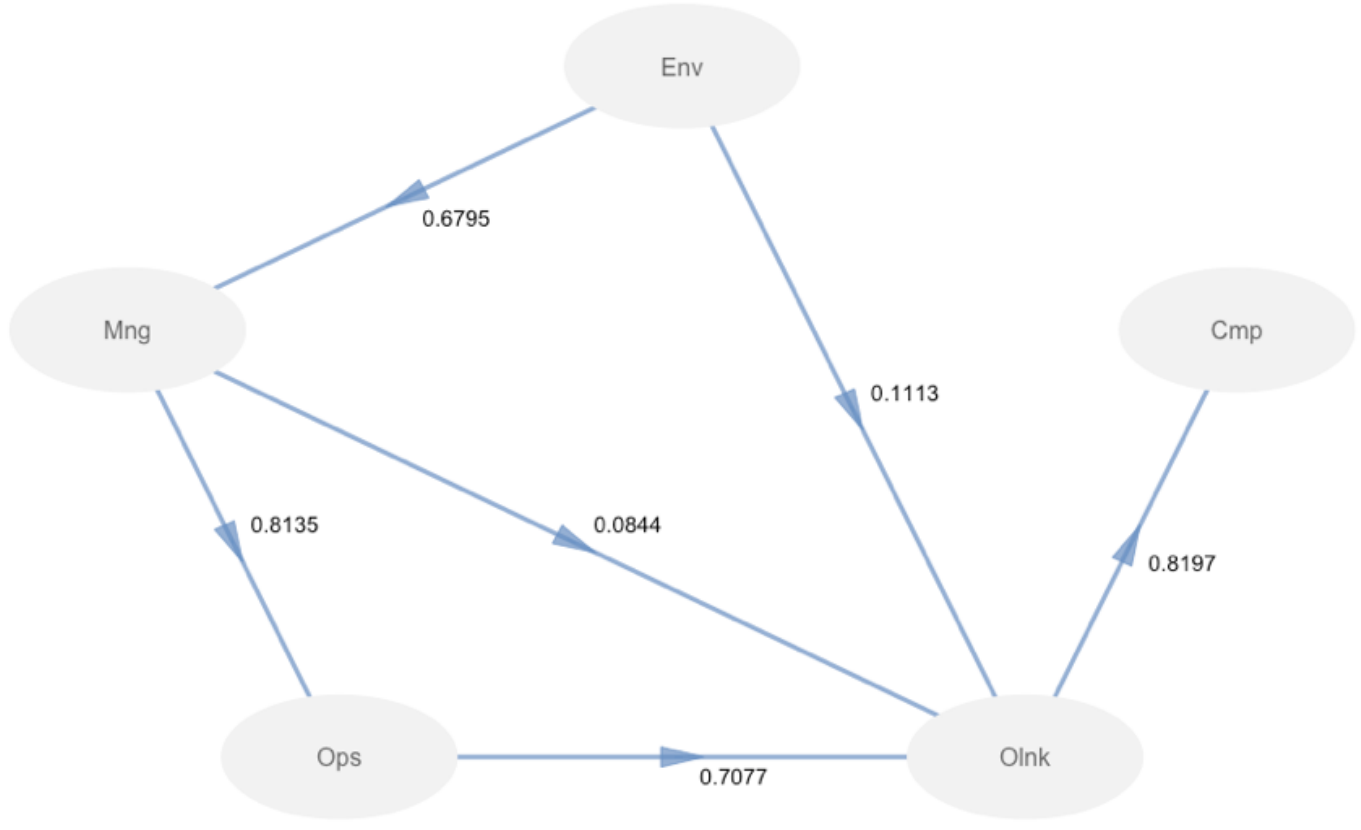

Source: self-elaboration using the plspm package in Rstudio

At this point, it is pertinent to note that the bootstrapping analysis validated the significance level of the relationships raised in Figure 5. According to Table 7, this analysis and the associated confidence interval indicate the degree of stability in the statistic of the sample as an estimation of the population parameter (Sanchez 2013). In this sense, if the confidence interval between perc.025 to perc. 975 does not contain the 0 value, the relationship in question is significant. Based on that, it is possible to accept four of the six hypotheses proposed in this article, given the absence of the 0 value of their respective intervals. That is, inter-organisational relationships and complementarity are unlikely to be encouraged if considering the environment (Env), management (Mng) or operations (Ops) separately. This finding implies that to promote complementarity, it is necessary to rethink the interactions among the operative units and their management and control mechanisms to make them able to interact in the same plane and thus jointly face changes in the context in which they operate.

Table 7 Bootstrapping analysis by latent variables, a confidence interval at $95 \%$ and their significance level

\begin{tabular}{ccccccc}
\hline & Original & Mean.Boot & Std.Error & perc.025 & perc.975 & Signf. \\
\hline Env -> Mng & 0.6795 & 0.6919 & 0.0498 & 0.5960 & 0.7845 & $* * *$ \\
Env -> Olnk & 0.1113 & 0.1133 & 0.1136 & -0.1123 & 0.3335 & ----- \\
Mng -> Ops & 0.8135 & 0.8182 & 0.0383 & 0.7377 & 0.8896 & $* * *$ \\
Mng -> Olnk & 0.0844 & 0.0824 & 0.1268 & -0.1597 & 0.3362 & $-\cdots-$ \\
Ops -> Olnk & 0.7077 & 0.7104 & 0.1539 & 0.3973 & 1.0091 & $* * *$ \\
Olnk -> Cmp & 0.8197 & 0.8230 & 0.0427 & 0.7345 & 0.8988 & $* * *$ \\
\hline
\end{tabular}




\section{Structuring complementarity through the viable system model}

The results obtained from the model also translate into implications for tourism SMEs. For example, regarding Env, the challenge is to integrate or develop a function that allows for the monitoring of the environment to obtain real information that is processed to improve operations and for sharing that information among the companies that are related under a complementarity scheme. To accomplish this, it is necessary to rethink how to relate the operations of these organisations with their management and control mechanisms to ensure the viability of inter-organisational relationships (Panagiotakopoulos et al. 2016). Based on this approach, the VSM is presented as an alternative and meta-language to model and structure the results obtained through the SSM and PLS-PM and thus to rethink the interactions of the tourism SMEs from the perspective of organisational cybernetics.

The VSM is integrated by 5 fundamental systemic functions (systems 1-5) that, when interacting, seek constant equilibrium (Azadeh et al. 2012). According to Schwaninger (1990), the VSM is suitable for bringing order to structural problems within organisations and closing the gap in soft or unstructured situations. In this regard, the application of each of these elements is described as follows:

- System 1 (S1): Contains those components of the organisation directly related to operations and essential activities aimed at fulfilling the organisational purpose. The units in this system must be autonomous enough to contribute to equilibrium and self-management; therefore, they must be designed to include the five systems.

- System 2 (S2): Responsible for coordination, this function uses resources such as rules, policies, and manuals to regulate the units that compose S1 and that act cohesively, that is, that they do not interfere in the activities of other units.

- Systems 3 and $3 *(\mathrm{~S} 3-\mathrm{S} 3 *)$ : Responsible for controlling and managing resources for the daily operation concerning the "here and now" of the organisation. S3* must support the S3 auditing and ensure that there is compliance with objectives expressed by S3 and the coordination's efforts of S2.

- System 4 (S4): Must monitor the environment in which the organisation operates, obtain relevant information about the external changes and combine this information with what S3 reported to facilitate the decision-making processes.

- System 5 (S5): Responsible for the management of the entire system. It should formulate policies and courses of action based on the information and data provided by the other systems and communicate them to $\mathrm{S} 3$ or implement them in S1. It is the only system that can intervene in descending form in the other functions to adjust the internal conflicts that affect the external response or impair the adaptation capability.

Based on the above, the design of the "ideal/must be" VSM is proposed to relate to different tourism SMEs under a complementarity scheme. This requires unfolding the complexity to locate the recursion level at which the application is performed. In this regard, Figure 6 shows four levels of recursion: First, (R0) concentrates the SMEs of the Mexican economy, and in this also nest three economic and strategic sectors for the country (R1). $\mathrm{R} 2$, the third recursion level, presents the elements of the service sector as well as the system in focus (tourist SMEs), where it seeks to generate complementarity between the mentioned companies. In this idea, the first three systems focus on core business activities. S4 and S5 seek to determine and adapt the complementarity among organisations to contrast some emerging situations that put part or all of a company at risk (Figure 7). 


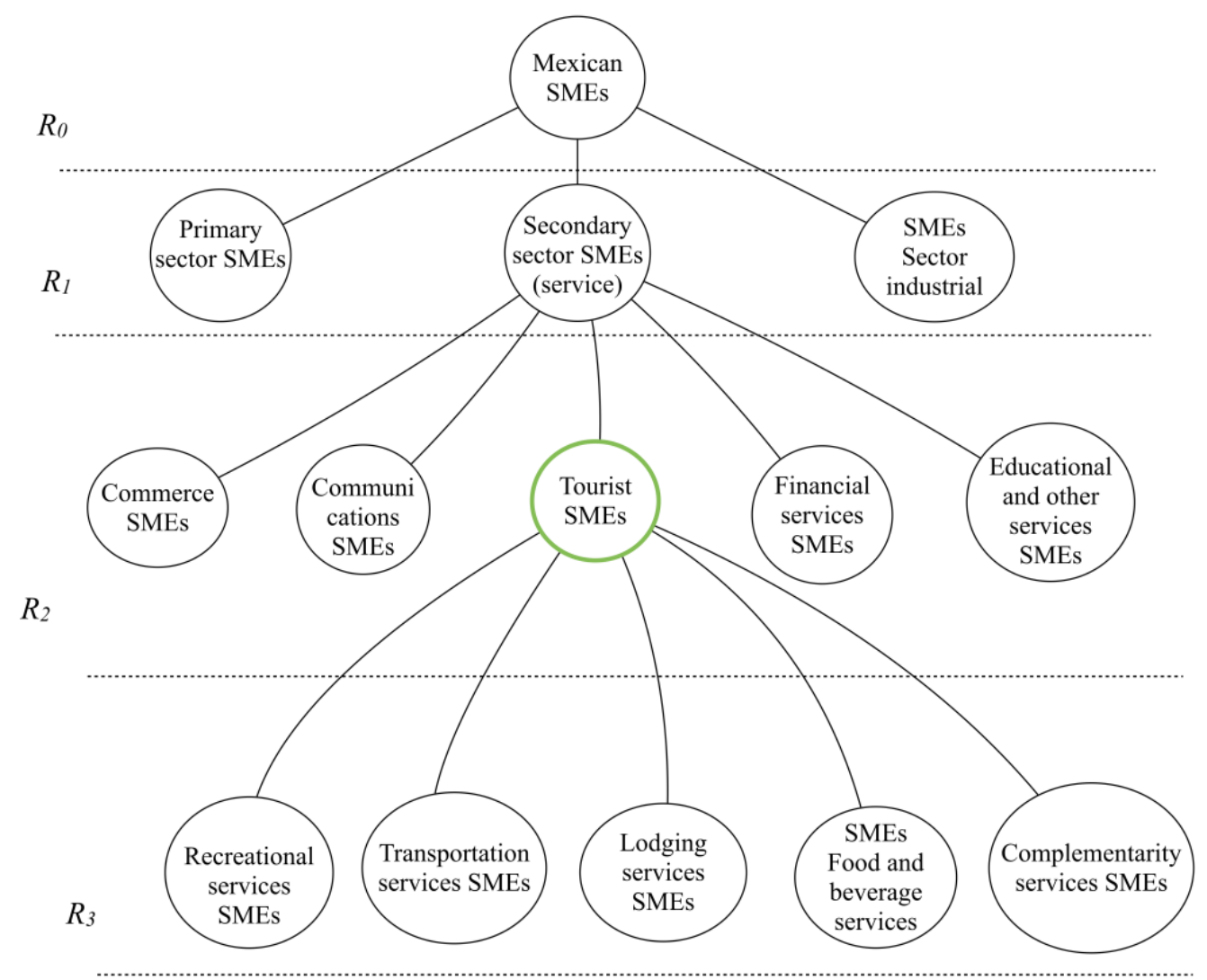

Figure 6 Unfolding complexity in tourist SMEs

Source: self-elaboration based on Beer (1985) 


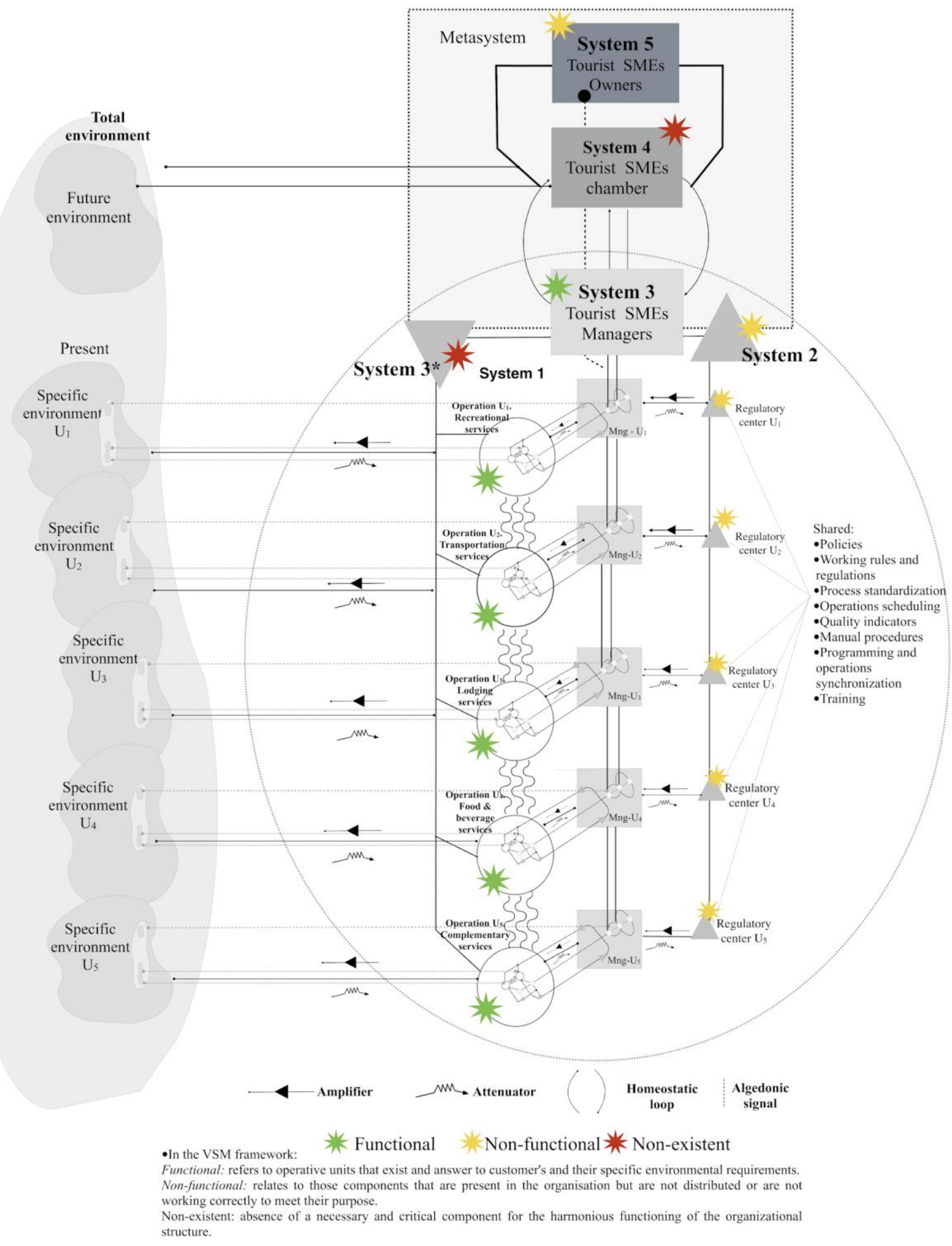

Figure 7 Viable system model for tourism SMEs

Source: Adapted from Beer (1985) and based on the SSM and PLS-PM results

The colours in Figure 7 indicate the current state of the relationship between the SMEs under study, identifying whether there are a lack of roles or varying levels of management. S1 is marked with green, as the essential operations of the system are identified by the type of organisation; these SMEs possess management mechanisms and have identified the specific environment to which they respond. In terms of coordination, S2 
is pointed out with yellow due to deficiencies in the exchange and transfer of information since companies, although they may communicate well, neither approve of nor share the same information level. As for S3* (indicated with red), there is no mechanism or function for monitoring overall SMEs, which implies that the operational units perform contrary actions and do not contribute to the identity of the whole. S4 is non-existent; this affects the system due to the lack of a mechanism that provides useful information that would allow adaptation to changes in the environment. Although S5 exists, it is non-functional, as it could equilibrate the performance of the whole system, the work as an entity is limited, and there are no shared tools for making decisions and jointly agreeing on the courses of action needed to be competitive. Figure 7 also suggests the ideal state or alternative change in considerations arising from the application of SSM and PLS-PM. In this sense, and considering the work of Cardoso Castro and Espinosa (2019), the design of the VSM, which aimed to promote the complementarity framework between tourism SMEs, is described in terms of its systems:

- System 1 (S1): Must fulfil the essential functions of the system and must operate looking for selforganisation. S1 requires implementing structured reports that allow proper dialogue with S3, updating its service status and sharing supplying needs. It is necessary to simplify communication processes to generate agreements and conventions between organisations that offer the same service, enabling a better supply for each of them. This must be done without neglecting relationships with other companies that offer different services but that coincide in the consumption of indirect inputs. This interaction ensures the supply chain of all companies.

- System 2 (S2): The lack of information is eliminated by standardising and integrating individual reports of each operative unit (company), thus promoting the construction of a database that can be shared in real-time with all companies. An example of this is keeping accounting records and establishing how to work jointly, use shared protocols for some problem or need, and have shared values, controls or indicators because there are problems that may not be able to be addressed individually.

- System 3 and System 3* (S3 - S3*): Should generate agreements between companies and those stakeholders that facilitate their activity. For this purpose, conventions can be used to access resources for suppliers, governments, and partnerships related to the development of SMEs. Additionally, S3 should promote the regulation of and commitment to collaborative work by continually reviewing the established production parameters and joint work. The inter-organisational performance should enable each company to procure efficiency in its products and services; this will be audited by S3* without interfering in the management of each operative unit.

- System 4 (S4): Managers from each SME must integrate the system; their intervention should facilitate the transduction of exogenous information to understand the conditions and changes in the tourism sector without circumventing the local economy. Additionally, this system is responsible for the forecasting and development process of the companies. To fulfil its function, the $\mathrm{S} 4$ can use internal or government databases and implement social network analysis or the monitoring of specialised tourism websites.

- System 5 (S5): Integrated for SMEs owners or managers, S5 should treat future adaptations and determine the rules of inter-organisational frameworks. The system is necessary for strengthening the identity of the cluster of SMEs regularly, and during that process, the ethos of the system must be disclosed. To fulfil its purpose, it can integrate quantitative decision-making processes, techniques or participatory methodologies for problem structuring.

\section{Discussion and Conclusion}

The results obtained for the Env variable converge with the ideas shared by Gallarza et al. (2013), Johnston et al. (2004), Moreno and Casillas (2008) and Valaei et al. (2017) that emphasise the development of individual capabilities to meet a global strategy. Although these results also indicate that SMEs have a distinctive structure that is limited to the environment, this article proposes supply chain competencies and distinctive organisational characteristics using the criteria of the VSM to reflect the flexibility that inter-organisational complementarity requires. Based on the estimations obtained for the Olnk variable, it is possible to say that inter-organisational coupling, as a track to complementarity, must necessarily consider the relationship between operational units, management mechanisms and the environment. In this regard, management (Mng) must adequately monitor 
changes in the environment and retrieve information to communicate accurately for homologating the courses of action of the operational units (Ops) without neglecting the communication processes between Mng and Env.

Communication processes are considered in the proposals made by F-Jardon and Pagani (2016), Jardon and Susana Martos (2012) and Westerlund and Rajala (2010). However, this relationship is assumed under a functionalist scheme that emphasises and prioritises management functions. In contrast, the proposed model considers feedback to be a communication mechanism that integrates the control and audit elements that promote the interrelation between SMEs without neglecting the impacts of the environment. Additionally, the contributions of Aboelmaged (2018), Kalkhouran et al. (2017), Lejpras (2019) and Zhang and Cao (2018) helped in identifying that although tourism companies recognise complementarity as an aspect that provides competitive advantages, in practical terms, complementarity requires balancing management, operations and control. In this regard, if each SME considers different aspects of the environment, they are unlikely to form inter-organisational relationships that are conducive to maintaining equilibrium. In this sense, the results in the Olnk variable allow for establishing that the relationship between environment-management operations is a factor that conditions the compatibility in relationships with other companies. Finally, the ideas developed in this work coincide with the findings of Carlisle et al. (2016), Torres et al. (2017), Serrano et al. (2018) and Sellitto et al. (2018) since the systems thinking factors and patterns to improve critical organisational aspects such as strategic planning and management are identified. This article also follows the path proposed by these authors regarding generating multi-methodological approaches. It should be added that although these contributions have evaluated the causal relationships and the different scenarios to ensure the success of a strategy, it is pertinent to recall that this article focuses on proposing and validating the relationships between components available in service SMEs' organisational structures to jointly adapt to disruptions in the environment. Both the protocol proposed from the SD and the systemic structures can complement and enrich this proposal by helping to evaluate the best associativity strategy or course of action. Based on this, the VSM is pertinent for proposing an organisational model that contrasts with the model usually employed by SMEs in the sector currently under study.

The literature review allowed us to identify that the different contributions that address aspects that affect the constructive relationships between SMEs are based on functionalist and structuralist criteria that emphasise the individual characteristics of the companies. This made it possible to verify the relevance of considering an integral perspective to propose models that specifically address the characteristics of SMEs to design proposals that consider the involved actors and their environment.

Under the framework of the systemic method, this study sought to congruently bind the methodological tools. The general purpose of the study was fulfilled by generating a conceptual model oriented towards SMEs to promote a form of organisation that supports these companies in responding to changes in their context. In this sense, the first particular objective of this article was reached with the application of the soft systems methodology, as the methodology served as a scaffold for structuring the problem, proposing a conceptual model that considers restating the relationships between the essential components of SMEs and promoting productive relationships oriented towards joint adaptation without neglecting the worldview of those involved. Following the direction of the soft systems methodology, a root definition was proposed, which gave meaning to the transformation process and the conceptual model. Therefore, this model integrates elements such as the environment in which the organisations operate, their basic operations and their management and control mechanisms to support the equilibrium.

The second objective of this article was to validate the construct using partial least squares path modelling, which found that the relationships established are consistent and congruent with the context in which the participants operate. It should be added that the results obtained for each hypothesis expressed in the model indicate that the variables consider aspects and functions shared by the studied SMEs, thus attending to the heterogeneity of the actors and avoiding focusing only on the management functions. The validation of the conceptual model also allowed us to determine that the aspects that tourism SMEs consider are determinant and affect both their field of action and their adaptation.

This approach allowed us to respond to a fundamental condition of the systemic method, which is to generate a shared model and to give way to the proposal of feasible and desirable changes by those involved. This presents implications from the organisational and relational points of view. Among these is the identification of organisational capacities that foster relationships with other companies and the capacities that 
emerge from the heterogeneous characteristics that allow them to correspond to their environment without neglecting the feedback mechanisms and the purpose of the system.

Considering the previous idea, the third objective was fulfilled by integrating the viable system model after validation with partial least squares path modelling. In this way, the viable system model was used as a tool to allow us to move from the conceptual arena to operational deployment and to propose an alternative for improving inter-organisational relationships under a scheme of complementarity. In addition to ordering the relationships, the application of the viable system model involves structuring the processes, respecting the autonomy of the operative units, and ensuring the generation of relevant information to enrich the decisionmaking processes.

It is crucial to state that the viable system model allowed an understanding of organisational pathologies between SMEs from a collaborative work scheme, and some of the most significant factors affecting this type of work are the organisational structures and the lack of systemic tenets in management models to recursively order functions to cope with the constraints of the environment. Addressing issues concerning the forms of associativity or collaboration is essential because it allows local companies to increase their opportunities to continue in the market, and the economic benefits of tourism activity can be distributed among these actors.

As a final idea, the methodological contribution of this article is to articulate systemic tools to validate a construct and propose a viable model for fostering productive relations among tourism SMEs while considering their capabilities and not neglecting the effects that the environment has on an organisation's management and the environment's direct impact on the courses of action that operative units follow. Conceptually, the intention is to contribute to the study of tourism SMEs as well as to propose the systems thinking framework to help with the study of unstructured situations. Finally, the ideas developed here also suggest, in practical terms, that managers need to consider changing from reductionist to holistic management styles.

\section{References}

Aboelmaged M (2018) The drivers of sustainable manufacturing practices in Egyptian SMEs and their impact on competitive capabilities: A PLS-SEM model. J Clean Prod 175:207-221. doi: 10.1016/j.jclepro.2017.12.053

Adham KA, Muhamad NS, Said MF, et al (2019) Diagnosing Business Incubation for Social Purpose: A Viable System Model Approach. Syst Pract Action Res 32:219-238. doi: 10.1007/s11213-018-9465-8

Al-Dmour RH, Love S, Al-Debei MM (2016) Factors influencing the organisational adoption of human resource information systems: a conceptual model. Int J Bus Innov Res 11:161-207

Ali Z, Sun H, Ali M (2017) The Impact of Managerial and Adaptive Capabilities to Stimulate Organizational Innovation in SMEs: A Complementary PLS-SEM Approach. Sustainability 9:2157. doi: $10.3390 / \mathrm{su} 9122157$

Armstrong R (2019) Elaborating a Critical Realist Approach to Soft Systems Methodology. Syst Pract Action Res 32:463-480. doi: 10.1007/s11213-018-9466-7

Azadeh A, Darivandi K, Fathi E (2012) Diagnosing, Simulating and Improving Business Process Using Cybernetic Laws and the Viable System Model: The Case of a Purchasing Process. Syst Res Behav Sci 29:66-86. doi: 10.1002/sres.1102

Beer S (1985) Diagnosing the system for the organization. John Wiley \& Sons, Londres

Cardoso Castro PP (2019) The viable system model as a framework to guide organisational adaptive response in times of instability and change. Int J Organ Anal 27:289-307. doi: 10.1108/IJOA-01-2018-1334

Cardoso Castro PP, Espinosa A (2019) Identification of organisational pathologies. Kybernetes K-10-20180557. doi: $10.1108 / \mathrm{K}-10-2018-0557$

Carlisle S, Johansen A, Kunc M (2016) Strategic foresight for (coastal) urban tourism market complexity: The case of Bournemouth. Tour Manag 54:81-95. doi: 10.1016/j.tourman.2015.10.005

Checkland P (2001) Systems thinking, systems practice, 2nd edn. Wiley, London

Cheng J-H (2011) Inter-organizational relationships and information sharing in supply chains. Int J Inf Manage 31:374-384. doi: 10.1016/j.ijinfomgt.2010.09.004

CNET (2018) Panorama de la actividad turística en México, información para la toma de decisiones de los empresarios. México

DeTombe D (2017) Societal problems more complex than presumed: The Compram methodology. J Syst Sci Syst Eng 26:303-320. doi: 10.1007/s11518-017-5334-8

Esposito Vinzi V, Chin WW, Henseler J, Wang H (eds) (2010) Handbook of Partial Least Squares. Springer Berlin Heidelberg, Berlin, Heidelberg 
F-Jardon CM, Pagani RN (2016) Is collective efficiency in subsistence clusters a growth strategy? The case of the wood industry in Oberá, Argentina. Int J Emerg Mark 11:232-255. doi: 10.1108/IJoEM-11-20130197

Fararah FS, Al-Swidi AK (2013) The Role of the Perceived Benefits on the Relationship between Service Quality and Customer Satisfaction: A Study on the Islamic Microfinance and SMEs in Yemen Using PLS Approach. Asian Soc Sci 9:. doi: 10.5539/ass.v9n10p18

Fornell C, Larcker DF (1981) Evaluating Structural Equation Models with Unobservable Variables and Measurement Error. J Mark Res 18:39. doi: 10.2307/3151312

Gallarza MG, Gil Saura I, Arteaga Moreno F (2013) The quality-value-satisfaction-loyalty chain: relationships and impacts. Tour Rev 68:3-20. doi: 10.1108/16605371311310048

Hanafizadeh P, Mehrabioun M, Badie K, Soofi JB (2018) A Systemic Framework for Business Model Design and Development -Part A: Theorizing Perspective. Syst Pract Action Res 31:437-461. doi: $10.1007 / \mathrm{s} 11213-017-9435-6$

INEGI (2017) Encuesta Nacional sobre Productividad y Competitividad de las Micro, Pequeñas y Medianas Empresas (ENAPROCE). México

Jardon CM, Susana Martos M (2012) Intellectual capital as competitive advantage in emerging clusters in Latin America. J Intellect Cap 13:462-481. doi: 10.1108/14691931211276098

Johnston DA, McCutcheon DM, Stuart FI, Kerwood H (2004) Effects of supplier trust on performance of cooperative supplier relationships. J Oper Manag 22:23-38. doi: 10.1016/j.jom.2003.12.001

Kalkhouran AA, Nedaei BH, Rasid SZA (2017) An exploratory investigation of an integrated model of costing practices in small and medium-sized enterprises. Int J Manag Financ Account 9:338. doi: 10.1504/IJMFA.2017.089061

Kanwal I, Lodhi RN, Kashif M (2019) Leadership styles and workplace ostracism among frontline employees. Manag Res Rev MRR-08-2018-0320. doi: 10.1108/MRR-08-2018-0320

Kerlinger FN (1986) Foundations of behavioral research. Holt, Rinehart and Winston, New York

Kirikova M, Businska L, Dubrovskis A, Salna E (2018) Viable Systems Model in Triple-Agile Context. In: Perspectives in Business Informatics Research. Springer, Cham, pp 158-171

Kline R (2011) Principles and Practice of Structural Equation Modeling, 3rd edn. THE GUILFORD PRESS, New York

Kock N (2018) Minimum Sample Size Estimation in PLS-SEM: An Application in Tourism and Hospitality Research. In: Faizan A, Mostafa Rasoolimanesh S, Cobanoglu C (eds) Applying Partial Least Squares in Tourism and Hospitality Research. Emerald Publishing Limited, p 264

Latan H (2018) PLS Path Modeling in Hospitality and Tourism Research: The Golden Age and Days of Future Past. In: Applying Partial Least Squares in Tourism and Hospitality Research. Emerald Publishing Limited, pp 53-83

Lejpras A (2019) Determinants of export performance: differences between service and manufacturing SMEs. Serv Bus 13:171-198. doi: 10.1007/s11628-018-0376-7

Maldonado-Guzmán G, Garza-Reyes JA, Pinzón-Castro SY, Kumar V (2017) Barriers to innovation in service SMEs: evidence from Mexico. Ind Manag Data Syst 117:1669-1686. doi: 10.1108/IMDS-082016-0339

Mancinelli S, Mazzanti M (2009) Innovation, networking and complementarity: evidence on SME performances for a local economic system in North-Eastern Italy. Ann Reg Sci 43:567-597. doi: $10.1007 / \mathrm{s} 00168-008-0255-6$

Marcoulides, Chin, Saunders (2009) A Critical Look at Partial Least Squares Modeling. MIS Q 33:171. doi: $10.2307 / 20650283$

Mendola D, Volo S (2017) Building composite indicators in tourism studies: Measurements and applications in tourism destination competitiveness. Tour Manag 59:541-553. doi: 10.1016/j.tourman.2016.08.011

Moore B, Calvo-Amodio J, Junker JF (2017) Applying a Framework for Complementarist Intervention Approaches to Service Organizations to Achieve a Sustainable Holistic Management Model. Syst Pract Action Res 30:487-513. doi: 10.1007/s11213-016-9403-6

Moreno AM, Casillas JC (2008) Entrepreneurial Orientation and Growth of SMEs: A Causal Model. Entrep Theory Pract 32:507-528. doi: 10.1111/j.1540-6520.2008.00238.x

Mulej M, Ženko Z, Žakelj V (2017) Social responsibility as a next step in development of systemic behavior toward systems solutions of systemic problems of today. J Syst Sci Syst Eng 26:287-302. doi: 10.1007/s11518-017-5333-9

Müller T, Schuberth F, Henseler J (2018) PLS path modeling - a confirmatory approach to study tourism 
technology and tourist behavior. J Hosp Tour Technol 9:249-266. doi: 10.1108/JHTT-09-2017-0106

Mwesiumo D, Halpern N (2016) Interfirm conflicts in tourism value chains. Tour Rev 71:259-271. doi: 10.1108/TR-07-2016-0020

Nakamori Y (2003) Systems methodology and mathematical models for knowledge management. J Syst Sci Syst Eng 12:49-72. doi: 10.1007/s11518-006-0120-z

Narvarte Arregui PA, Careaga Díaz C (2015) El modelo del sistema viable: una referencia estratégica para el estudio organizacional del sector cooperativo chileno. REVESCO Rev Estud Coop 121:173-204. doi: 10.5209/rev_REVE.2016.v121.49702

Nikraftar T, Hosseini E (2016) Factors affecting entrepreneurial opportunities recognition in tourism small and medium sized enterprises. Tour Rev 71:6-17. doi: 10.1108/TR-09-2015-0042

Núñez-Ríos JE, Sánchez-García JY, Tejeida-Padilla R, Coria-Páez AL (2018) Human capital management innovation for Mexican lodging through autopoiesis and self-organisation. In: 62nd Annual Meeting of the International Society for the Systems Sciences, ISSS 2018: Innovation and Optimization in Nature and Design. International Society for the Systems Sciences (ISSS), pp 125-140

Nunez-Rios JE, Sánchez-García JY, Tejeida-Padilla R, Soto-Perez M (2019) A Systems Science Approach to Structure Human Capital Management in Mexican Lodging SMEs. Int J Appl Syst Stud Inpress:

OECD (2017) Small, Medium, Strong. Trends in SME Performance and Business Conditions. OECD Publishing, Paris

Panagiotakopoulos PD, Espinosa A, Walker J (2016) Sustainability management: insights from the Viable System Model. J Clean Prod 113:792-806. doi: 10.1016/j.jclepro.2015.11.035

Presenza A, Cipollina M (2010) Analysing tourism stakeholders networks. Tour Rev 65:17-30. doi: $10.1108 / 16605371011093845$

Price J (1997) Handbook of organizational measurement. Int J Manpow 18:305-558

Ramírez-Gutiérrez AG (2019) Modelo Sistémico Viable para el Turismo de Reuniones en México. Instituto Politécnico Nacional

Recuero Virto N, Blasco López MF, San-Martín S (2017) How can European museums reach sustainability? Tour Rev 72:303-318. doi: 10.1108/TR-03-2017-0038

Rezaee Z, Azar A, Erz AMB, Nayeri MD (2019) Application of Viable System Model in Diagnosis of Organizational Structure. Syst Pract Action Res 32:273-295. doi: 10.1007/s11213-018-9454-y

Romero-García LE, Aguilar-Gallegos N, Morales-Matamoros O, et al (2019) Urban tourism: a systems approach - state of the art. Tour Rev 74:679-693. doi: 10.1108/TR-06-2018-0085

Rousseau D, Wilby J, Billingham J, Blachfellner S (2018) The Knowledge Base of General Systemology. pp 79-104

Sánchez-García JY, Núñez-Ríos JE, Badillo-Piña I (2018) Innovation in services: A viable system model design for tourist MSMES integration in México. In: 62nd Annual Meeting of the International Society for the Systems Sciences, ISSS 2018: Innovation and Optimization in Nature and Design. International Society for the Systems Sciences (ISSS), Corvallis, pp 141-153

Sanchez G (2013) PLS Path Modeling with R Trowchez Editions. In: Berkeley. http://www.gastonsanchez.com/PLS Path Modeling with R.pdf

Sánchez Y, Hernández N, Zerón M (2017) Estrategias de negocio en pymes familiares del norte de México: estudio comparativo. Rev Venez Gerenc 22:351-367

Sarstedt M, Ringle CM, Gudergan SP (2016) Guidelines for treating unobserved heterogeneity in tourism research: A comment on Marques and Reis (2015). Ann Tour Res 57:279-284. doi: 10.1016/j.annals.2015.10.006

Schwaninger M (2018) Systemic design for sustainability. Sustain Sci 13:1225-1234. doi: 10.1007/s11625018-0538-5

Schwaninger M (1990) Embodiments of organizational fitness: The Viable System Model (VSM) as a guide. Syst Pract 3:249-264. doi: 10.1007/BF01062731

Sedarati P, Santos S, Pintassilgo P (2019) System Dynamics in Tourism Planning and Development. Tour Plan Dev 16:256-280. doi: 10.1080/21568316.2018.1436586

Sellitto MA, Pereira GS, Marques R, Lacerda DP (2018) Systemic Understanding of Coopetitive Behaviour in a Latin American Technological Park. Syst Pract Action Res 31:479-494. doi: 10.1007/s11213-0179439-2

Serrano R, Rodrigues LH, Lacerda DP, Paraboni PB (2018) Systems Thinking and Scenario Planning: Application in the Clothing Sector. Syst Pract Action Res 31:509-537. doi: 10.1007/s11213-017-9438-3

Shahabi A, Azar A, Radfar R, Asadifard RA (2019) Combining Soft Systems Methodology with Interpretive 
Structural Modeling and System Dynamics for Network Orchestration: Case Study of the Formal Science and Technology Collaborative Networks in Iran. Syst Pract Action Res. doi: 10.1007/s11213019-09490-z

Soltanizadeh S, Abdul Rasid SZ, Mottaghi Golshan N, Wan Ismail WK (2016) Business strategy, enterprise risk management and organizational performance. Manag Res Rev 39:1016-1033. doi: 10.1108/MRR05-2015-0107

Tiedemann N, van Birgele M, Semeijn J (2009) Increasing hotel responsiveness to customers through information sharing. Tour Rev 64:12-26. doi: 10.1108/16605370911004548

Torres JP, Kunc M, O’Brien F (2017) Supporting strategy using system dynamics. Eur J Oper Res 260:10811094. doi: 10.1016/j.ejor.2017.01.018

Usakli A, Kucukergin KG (2018) Using partial least squares structural equation modeling in hospitality and tourism. Int J Contemp Hosp Manag 30:3462-3512. doi: 10.1108/IJCHM-11-2017-0753

Vahidi A, Aliahmad A, Teimouri E (2019) Evolution of Management Cybernetics and Viable System Model. Syst Pract Action Res 32:297-314. doi: 10.1007/s11213-019-9478-y

Vahidi A, Aliahmadi A (2019) Describing the Necessity of Multi-Methodological Approach for Viable System Model: Case Study of Viable System Model and System Dynamics Multi-Methodology. Syst Pract Action Res 32:13-37. doi: 10.1007/s11213-018-9452-0

Valaei N (2017) Organizational structure, sense making activities and SMEs' competitiveness. VINE J Inf Knowl Manag Syst 47:16-41. doi: 10.1108/VJIKMS-04-2016-0015

Valaei N, Rezaei S, Ismail WKW (2017) Examining learning strategies, creativity, and innovation at SMEs using fuzzy set Qualitative Comparative Analysis and PLS path modeling. J Bus Res 70:224-233. doi: 10.1016/j.jbusres.2016.08.016

Vihari NS, Rao MK, Jada U (2018) Empirical linkage between sustainable HRM and organisational flexibility: a SEM-based approach. Int J Bus Innov Res 17:65-86

Westerlund M, Rajala R (2010) Learning and innovation in inter-organizational network collaboration. J Bus Ind Mark 25:435-442. doi: 10.1108/08858621011066026

Wu I-L, Chuang C-H, Hsu C-H (2014) Information sharing and collaborative behaviors in enabling supply chain performance: A social exchange perspective. Int J Prod Econ 148:122-132. doi: 10.1016/j.ijpe.2013.09.016

Zhang Q, Cao M (2018) Exploring antecedents of supply chain collaboration: Effects of culture and interorganizational system appropriation. Int J Prod Econ 195:146-157. doi: 10.1016/j.ijpe.2017.10.014 